\title{
Suppression of postpellet licking by a Pavlovian S+
}

\author{
WENDELL STONE \\ University of Missouri, Columbia, Missouri 65201 \\ DAVID O. LYON \\ Western Michigan University, Kalamazoo, Michigan 49001 \\ and \\ DOUGLAS ANGER \\ University of Missouri, Columbia, Missouri 65201
}

\begin{abstract}
Two experiments were performed on rats to determine the effect on postpellet licking of preceding a pellet with a 15-sec tone. Experiment 1, a group design, showed less licking during a tone consistently followed by a pellet than during a tone not consistently followed by a pellet. In Experiment 2, within-subjects comparisons were made of postpellet licking rates during the presence vs. absence of a tone followed by additional pellets, and consistent reductions of licking during the later portions of the tone were found. The results support the notion that licking is produced by a Pavlovian S- .
\end{abstract}

The spaced delivery of $45-\mathrm{mg}$ Noyes pellets to fooddeprived rats generates characteristic patterns of licking. This schedule-induced licking occurs on a variety of interval and ratio schedules of reinforcement and food delivery. Although the licking is almost exclusively a postpellet phenomenon, recent investigations have suggested that licking can be conditioned to occur to a nonfood stimulus. For example, Segal and Deadwyler (1965) reported licking following clicks from an empty food dispenser during extinction of responding maintained by differential reinforcement of low response rates. In addition, Rosenblith (1970) and Wuttke and Innis (1972) observed licking following the signaled completion of individual components of a second-order schedule. Rosenblith (1970) proposed that the licking was due to the pairing of the signal with a pellet in the terminal component of the schedule.

According to Rosenblith's explanation, the rate of licking during a stimulus preceding a pellet should be higher than during a stimulus presented randomly with respect to a pellet. Two experiments were performed to investigate the effect on licking of preceding a pellet with a 15 -sec tone.

\section{EXPERIMENT 1}

\section{Method}

The subjects were four male rats maintained at $80 \%$ of adlib weight. Two similar sound-attenuated chambers were used, each equipped with drink tube, food cup, and tone generator.

Reprints may be obtained from Wendell Stone, Department of Psychology, University of Missouri, Columbia, Missouri 65201.
All rats received one session of magazine training consisting of the delivery of 40 pellets over a period of 40 to $45 \mathrm{~min}$. Two animals, E1 and E2, were then exposed to a trial procedure (variable intertrial interval, averaging $75 \mathrm{sec}$ ) in which a 15 -sec tone was presented before the delivery of each pellet. For $\mathrm{C1}$ and $\mathrm{C} 2$, however, the pellet occurred at varying times with respect to the tone. The mean interval between tones and between pellets was the same as for E1 and E2. All rats were exposed to 15 daily sessions with 100 tones/session.

\section{Results}

The rate of licking during the tone, expressed as a percentage of the total number of licks occurring during each session, is plotted for all rats in Figure 1. Both E1 and E2 showed an initial sharp decrease in licking rate, followed by a gradual increase, although the rate remained low. Based on all 15 sessions, E1 and E2 averaged $7.2 \%$ and $5.1 \%$ of the total session licks during the tone. $\mathrm{C} 1$ and $\mathrm{C} 2$ had more stable rates of licking

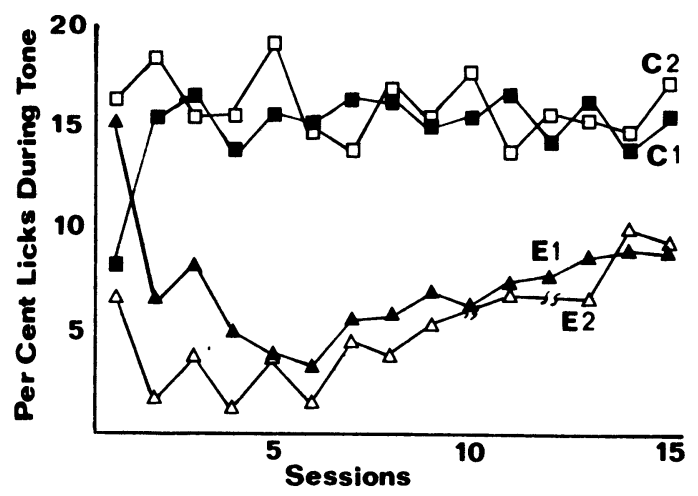

Figure 1. Percent of total session licks during tone. 
during the tone that were consistently higher than the rates of $\mathrm{E} 1$ and $\mathrm{E} 2$. Average rates for $\mathrm{C} 1$ and $\mathrm{C} 2$, respectively, were $14.9 \%$ and $16.0 \%$.

\section{Discussion}

These data indicate that when a pellet consistently follows a tone, licking during the tone is reduced compared with the licking that occurs during the tone if the tone is not related to pellet delivery. For all rats, the tone was present for an average of $17 \%$ of the total session time. Since $\mathrm{C} 1$ and $\mathrm{C} 2$ showed licking rates close to $17 \%$ from the second day on, the tone had little, if any, effect on their behavior. Thus, their behavior provides a reasonable baseline for comparison with the effect of the pairing on E1 and E2. Experiment 2 was performed to further examine this suppression using within-subjects comparisons.

\section{EXPERIMENT 2}

\begin{abstract}
Method
Three male rats maintained at $80 \%$ of ad-lib weight were the subjects, and the two chambers from Experiment 1 and a third similar chamber were used. Following magazine training, pellets were deliverd every $90 \mathrm{sec}$ on a fixed-time basis (FT $90 \mathrm{sec}$ ). The delivery of a pellet and the first $15 \mathrm{sec}$ of the postpellet period constituted a trial. Two types of trials were given during each session. On tone trials, a tone came on immediately after delivery of a pellet, and at the end of the 15-sec tone a second pellet was delivered. On no-tone trials, no tone or second pellet occurred. Twenty tone trials and 80 no-tone trials, delivered in a variable sequence, made up each daily 100 -trial session. After 16 sessions of this procedure, the number of pellets at the end of the tone was changed from one, to two, to four, and, finaily, to zero pellets, with six sessions of each condition.
\end{abstract}

\section{Results}

The 15-sec period following the delivery of each FT 90-sec pellet was divided into successive 5 -sec segments and the mean number of licks occurring in each segment for each condition was computed separately for tone and no-tone trials. These data are plotted in Figure 2. Each data point is an average of all three rats and is based on all sessions at each condition, except for the first (one-pellet) condition, where only the last six sessions were used. The mean licks/trial on both types of trials was always low in the first third of the trial (usually 5-13 licks). (This low rate was, of course, largely a result of the latency between pellet delivery and initiation of licking.) Lick rates on tone trials were slightly but consistently higher during this first third of the trial. The rate of licking rose sharply in the middle third of the trial (24-34 licks), with no systematic difference between tone and no-tone trials. During the final third, the licking rates remained high (26-31 licks) without the tone, but showed consistently lower rates during the tone (12-18 licks). (Of the 54 comparisons, 53 showed lower lick rates on tone trials.) The size of this effect was not changed appreciably by changes in the number of pellets delivered at the end of the tone. The mean differences between tone and notone rates in the last third of the trial varied less than four licks between the one-, two-, and four-pellet condi-

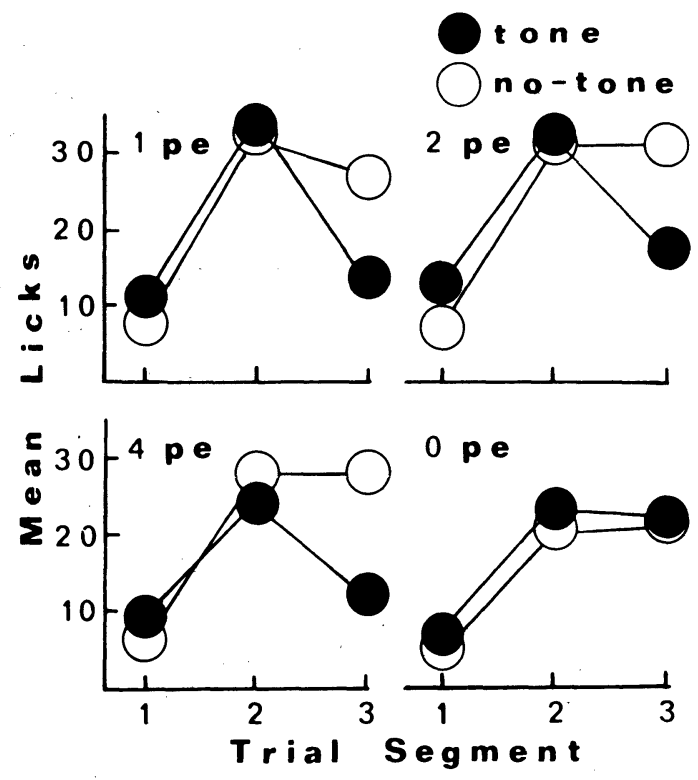

Figure 2. Licking rate as a function of trial segment.

tions. During the zero-pellet condition, the rates with and without the tones were essentially equal in the last trial segment.

\section{Discussion}

These data show that when a stimulus followed by food is superimposed on a substantial rate of postpellet licking, there is a decrease in that rate in the later part of the stimulus. Longer training probably would decrease licking during the middle third too, because such licking by two of the rats was decreasing toward the end of the treatments with additional pellets. These within-subjects data confirm the between-subjects data obtained in Experiment 1, where a similar suppressing effect of the pairing was observed.

\section{GENERAL DISCUSSION}

The Pavlovian conditioning procedures reported here resulted in a decrease rather than an increase in licking. The explanation may be that the pellet does not directly evoke licking. On schedules that generate postpellet licking, the probability of a pellet is lower following a pellet than at other times; hence, the postpellet period is a Pavlovian $\mathrm{S}_{-}$, and that may produce the licking.

The proposal that a Pavlovian S- is critical for the production of licking is not new and has been supported by several investigations. For example, Keehn and Colotla $(1970,1971)$ reinforced barpressing on mix fixed-interval (FI) t-sec continuousreinforcement $(n)$ schedules of pellet delivery and found that rats did not lick after every pellet, but continued to respond until $\mathrm{n}$ pellets had been delivered; only after barpresses went unreinforced did they begin to lick. Furthermore, when rats were reinfroced on a mix FI 15-sec 120-sec schedule (Colotla, Keehn, \& Gardner, 1970), more licking was observed in the longer interval, suggesting to these authors that the unavailability of food sets the occasion for licking to begin and the reavailability of food sets the occasion for licking to end. Staddon (1977) and Staddon and Simmelhag (1971) in their discussion of interim behavior also clearly express the role of stimuli that signal the absence of food in generating licking. 
Both of the present experiments support the view that licking is produced by a Pavlovian S-. Experiment 1 showed that licking during a tone decreased when the tone became a Pavlovian S+. Experiment 2 showed that licking during the postpellet period, which is ordinarily a Pavlovian $\mathrm{S}-$, was reduced by additional pellets at that time. Thus, pellets do not seem to directly produce licking, because, if they did, Pavlovian conditioning should increase licking during a tone before a pellet. Instead, these results indicate that the pellet only indirectly produces licking by signaling a low pellet frequency, which in turn produces licking. Hence, licking is reduced by additional pellets soon after the first one.

\section{REFERENCES}

AzRIN, N. H., \& Hake, D. F. Positive conditioned suppression: Conditioned suppression using positive reinforcers as the unconditioned stimuli. Journal of the Experimental Analysis of Behavior, 1969, 12, 167-173.

Colotla, V. A., Keehn, J. D., \& Gardner, L. L. Control of schedule-induced drink durations by interpellet intervals. Psychonomic Science, 1970, 21, 137-139.

Kerhn, J. D., \& Colotla, V. A. Prediction and control of schedule-induced drink durations. Psychonomic Science, 1970, 21. 147-148.
Keehn, J. D., \& Colotla, V. A. Stimulus and subject control of schedule-induced drinking. Journal of the Experimental Analysis of Behavior, 1971, 16, 257-262.

Rosenblith, J. Z. Polydipsia induced in the rat by a second-order schedule. Journal of the Experimental Analysis of Behavior, 1970, 14, 139-144.

Segal, E. F., \& Deadwyler, S. A. Determinants of polydipsia in rats: 2.DRL extinction. Psychonomic Science, 1965, 2 , 203-204.

Staddon, J. E. R. Schedule-induced behavior. In W. K. Honig \& J. E. R. Staddon (Eds.), Handbook of operant behavior. Englewood Cliffs, N.J: Prentice-Hall, 1977. Pp. 125-152.

Staddon, J. E. R., \& Simmelhag, V. L. The "superstition" experiment: A reexamination of its implications for the principles of adaptive behavior. Psychological Review, 1971, 78, 3-43.

WutTke, W., \& INNIS, N. K. Drug effects upon behavior induced by second-order schedules of reinforcement: The relevance of ethological analyses. In R. M. Gilbert \& J. D. Keehn (Eds.), Schedule effects: Drugs, drinking, and aggression. Toronto: University of Toronto Press, 1972. Pp. 129-147.

(Received for publication April 24, 1978.) 